\title{
Prognostic role of serum cytokeratin 19 fragments in advanced non-small-cell lung cancer: association of marker changes after two chemotherapy cycles with different measures of clinical response and survival
}

\author{
B Nisman*,', H Biran', N Heching', V Barak', N Ramu', I Nemirovsky' and T Peretz' \\ 'Department of Oncology, Hadassah University Hospital, Jerusalem, Israel; '2Lung Cancer Unit, Division of Oncology, Sheba Medical Center, \\ Tel Hashomer, Israel
}

Prognostic implication of serum cytokeratin 19 fragments (CYFRA $21-1$ ) was explored in 60 advanced NSCLC patients, whereas in 45 patients assessable for serological response $\mathrm{a} \geqslant 35 \%$ CYFRA 2 I - I decline after two chemotherapy cycles was strongly associated with non-progression (NP), defined as a sum of objective response $(\mathrm{OR})+$ stable disease $(P<0.000 \mathrm{I})$ and survival $(P=0.0002)$. Association of OR with survival was not significant. In multivariate survival analysis, $\geqslant 35 \%$ marker decline and radiological NP status were found as major determinants of prolonged survival with RR: $0.37(P=0.0 \mathrm{I})$ and $0.63(P=0.0 \mathrm{I})$, respectively. In advanced NSCLC patients, NP reflects therapeutic efficacy better than traditional OR. CYFRA $21-1 \geqslant 35 \%$ decline seems to be a reliable surrogate marker of treatment efficacy in terms of survival.

British Journal of Cancer (2008) 98, 77-79. doi:I0.1038/sj.bjc.6604I57 www.bjcancer.com

Published online 18 December 2007

(c) 2007 Cancer Research UK

Keywords: CYFRA 2I-I; non-small-cell lung carcinoma; clinical response; survival prediction

Combination chemotherapy for advanced non-small-cell lung cancer (NSCLC) is clinically beneficial in only about half of the treated naive patients, and most responses are partial.

The decision whether to continue or to stop therapy is traditionally guided by imaging-based tumour response evaluation, which is regarded a surrogate marker of clinical benefit. Assessment by structural imaging has known limitations and also may have a poor correlation with pathologic response in NSCLC (Martini et al, 1988).

Furthermore, it has been shown that objective response (OR) is not a wholly reliable prognosticator of survival (Gandara et $a l, 1999)$. In this context, the diagnostic and prognostic potential of biochemical markers, such as circulating cytokeratin 19 fragments (CYFRA 21-1), in monitoring antineoplastic therapy has been investigated (Ebert and Muley 1999, Ardizzoni et al, 2006).

In the present study, we compared CYFRA 21-1 change with clinical response after two chemotherapy cycles in order to find out which one correlates better with patients' survival.

*Correspondence: Dr B Nisman; E-mail: nisman@hadassah.org.il Received 23 July 2007; revised 21 November 2007; accepted 23 November 2007; published online 18 December 2007

\section{PATIENTS AND METHODS}

\section{Patients}

This prospective, IRB approved, study included 60 chemotherapy-naive patients enrolled between 1 January 1998 and 1 July 2003. Patient characteristics are presented in Table 1 . The median age was 61 years (37-77 years). All patients received a minimum of two, and up to eight (median 5) chemotherapy cycles (= courses). Specific regimens are presented in Table 1. CT scans were performed every two cycles. All patients had measurable disease. A functional state was graded by the Eastern Cooperative Oncology Group (ECOG) performance status (PS) scale.

Two response categories were explored: OR (complete response $(\mathrm{CR})+$ partial response $(\mathrm{PR}))$ and non-progression - NP $(C R+P R+$ stable disease (SD)). Patients achieving either OR or NP were classified as responders, whereas those with no response $(\mathrm{NR})(\mathrm{SD}+$ progressive disease $(\mathrm{PD}))$ or $\mathrm{PD}$, respectively, were considered non-responders.

\section{Methods}

Serum samples were obtained before the start and after the second chemotherapy course at the time of clinical response evaluation and stored at $-80^{\circ} \mathrm{C}$ until analysis. Cytokeratin 19 fragments were measured by immunoradiometric ELSA-CYFRA 21-1 kit (CIS Bio International, Gif-sur Yvette, France). The cut-off value was $3.2 \mathrm{ng} \mathrm{ml}^{-1}$. It provided $95 \%$ specificity in the group of patients 
with benign lung diseases (Nisman et al, 1998). From two serum samples, pretreatment and that obtained after two cycles of chemotherapy, at least one was required to be above the normal cut-off $\left(3.2 \mathrm{ng} \mathrm{ml}^{-1}\right)$ to have the CYFRA 21-1 change assessable disease.

\section{Statistical analysis}

Non-parametric tests were used for comparisons between numeric variables, the Wilcoxon signed-rank test for CYFRA 21-1 before and after treatment and Mann-Whitney for independent groups. Spearman's correlations were reported. Associations between categorical variables were evaluated with the $\chi^{2}$-test. The Youden index was used to identify the optimal decline in CYFRA 21-1 for the diagnosis of NP or OR (Armitage, 1971). Univariate analyses of the prognostic impact of various factors on survival from response evaluation (i.e., landmark time of 6 weeks) to death or last follow-up used the Kaplan-Meier method and log-rank test. Variables statistically significant $(P<0.05)$ in the univariate steps were entered into multivariate Cox regression models (Cox, 1972). The proportional hazard assumption was examined in log minus $\log$ plots and found acceptable. A value of $P<0.05$ was considered significant.

\section{RESULTS}

\section{Whole study population $(N=60)$}

Pre- and post-treatment, two-course median CYFRA 21-1 were $5.5 \mathrm{ng} \mathrm{ml}^{-1}$ (range $0.89-88.6 \mathrm{ng} \mathrm{ml}^{-1}$ ) and $2.2 \mathrm{ng} \mathrm{ml}^{-1}$ (range $0.28-64.1 \mathrm{ng} \mathrm{ml}^{-1}$ ), respectively. Between two consecutive measurements, CYFRA 21-1 showed a significant decline $(P=0.001)$.

Table I Patient and disease characteristics

\begin{tabular}{|c|c|}
\hline Characteristics & $n$ \\
\hline \multicolumn{2}{|l|}{ Gender } \\
\hline Males/Females & $43 / 17$ \\
\hline \multicolumn{2}{|l|}{ Age (years) } \\
\hline$\leqslant 61 />61$ & $32 / 28$ \\
\hline \multicolumn{2}{|l|}{ Stage } \\
\hline$\|\mathrm{I} /\| \mathrm{II} / \mathrm{IV}$ & $5 / 18 / 37$ \\
\hline \multicolumn{2}{|l|}{ ECOG PS } \\
\hline $0-1 / 2$ & $41 / 19$ \\
\hline \multicolumn{2}{|l|}{ Tumour histology } \\
\hline Adenocarcinoma & 29 \\
\hline Squamous & 9 \\
\hline Large cell & 17 \\
\hline Unclassified NSCLC & 5 \\
\hline \multicolumn{2}{|l|}{ First line chemotherapy } \\
\hline Cisplatin+gemcitabine & 29 \\
\hline Carboplatin+paclitaxel & 23 \\
\hline Carboplatin+etoposide & 6 \\
\hline Others & 2 \\
\hline \multicolumn{2}{|l|}{ Clinical response } \\
\hline CR/PR/SD/PD & $|/| 6 / 22 / 21$ \\
\hline \multicolumn{2}{|l|}{ Status at last follow-up } \\
\hline Alive/dead of tumour & 1/59 \\
\hline
\end{tabular}

Median marker change in OR $(-76 \%)$ was close to that of SD $(-58 \%)(\mathrm{P}=0.7)$, but significantly higher than that in $\mathrm{PD}(5 \%)$ $(P=0.003)$.

In OR and NR subgroups, the median CYFRA 21-1 changes after two courses did not differ significantly $(-76$ and $-34 \%$, respectively, $P=0.1)$; whereas in $\mathrm{NP}$, the median change was significantly larger than in PD (-68 and 5\%, respectively, $P=0.001)$.

CYFRA 21-1 levels were above the cut-off limit $\left(3.2 \mathrm{ng} \mathrm{ml}^{-1}\right)$ in $43(71.7 \%)$ and in $24(40 \%)$ of 60 patients pre- and post-treatment two courses, respectively. In only 2 out of 60 patients $(3.3 \%)$, elevation greater than cut-off level occurred during initial therapy.

Overall median survival from the landmark time was 12.7 months. Median survival of either OR and or SD patients was significantly longer than that of PD patients (16.3 and 14 vs 6.1 months; $P<0.0001$ and $P=0.0005$, respectively), whereas $\mathrm{OR}$ and SD patients were similar $(P=0.69)$. Non-progression patient's median survival was 15.1 months.

Table 2 depicts patient characteristics, biochemical parameters and the response category, associated with survival. Association of OR with survival did not reach statistical significance $(P=0.06)$. When pretreatment significant parameters were included in the Cox model, an independent prognostic status was retained for PS (relative risk (RR): 2.0; 95\% CI 1.1-3.5; $P=0.03$ ), stage (RR: $1.9 ; 95 \%$ CI $1.1-3.4 ; P=0.02)$ and pre-treatment CYFRA $21-1$ (1-CYFRA 21-1) (RR: $0.5 ; 95 \%$ CI $0.3-0.9 ; P=0.02$ ). When, however, the aforementioned three variables were complemented by post-treatment two courses CYFRA 21-1 (2-CYFRA 21-1) and $\mathrm{NP}$, only the latter two stayed independent with a RR: $0.40 ; 95 \% \mathrm{CI}$ $0.19-0.84 ; P=0.01$ and RR: $0.55 ; 95 \%$ CI $0.39-0.76, P<0.001$, respectively.

\section{Subgroup of patients with CYFRA 21-1 change assessable disease $(N=45)$}

According to the used criterion presented in the method section, 45 patients were found to have disease assessable for marker

Table 2 Univariate survival analyses in 60 patients with NSCLC (only variables with $P<0.1$ were included)

\begin{tabular}{|c|c|c|c|c|}
\hline Characteristics & $\mathbf{N}$ & MS (months) & $95 \% \mathrm{Cl}$ & $P$-value log rank \\
\hline \multicolumn{5}{|l|}{ Stage } \\
\hline$\|A-\| B$ & 23 & 13.7 & $11.7-15.7$ & \multirow[t]{2}{*}{0.04} \\
\hline IV & 37 & 8.9 & $3.9-13.9$ & \\
\hline \multicolumn{5}{|l|}{ ECOG PS } \\
\hline$\leqslant 1$ & 41 & 13.0 & $|0.9-| 5 . \mid$ & \multirow{2}{*}{0.02} \\
\hline$>1$ & 19 & 7.5 & $1.4-13.6$ & \\
\hline \multicolumn{5}{|l|}{ NP } \\
\hline Yes & 39 & 15.1 & $13.0-17.2$ & \multirow{2}{*}{$<0.000$ । } \\
\hline No & 21 & 6.1 & $2.7-9.5$ & \\
\hline \multicolumn{5}{|l|}{$O R$} \\
\hline Yes & 17 & 16.3 & $11.0-21.6$ & \multirow[t]{2}{*}{0.06} \\
\hline No & 43 & 8.8 & $3.9-13.6$ & \\
\hline \multicolumn{5}{|c|}{ I-CYFRA 2 I-I $\left(\mathrm{ng} \mathrm{m}^{-1}\right)$} \\
\hline$\leqslant 3.2$ & 17 & 19.5 & $11.4-27.6$ & \multirow[t]{2}{*}{0.01} \\
\hline$>3.2$ & 43 & 10.6 & $5.8-15.4$ & \\
\hline \multicolumn{5}{|c|}{ 2-CYFRA 2l-I (ng mll- $)$} \\
\hline$\leqslant 3.2$ & 36 & 15.1 & $13.5-16.7$ & \multirow[t]{2}{*}{$<0.000$ । } \\
\hline$>3.2$ & 24 & 6.2 & $5.2-7.2$ & \\
\hline
\end{tabular}

|-CYFRA 2 $1-1$ = pretreatment CYFRA 2 $1-1$; 2-CYFRA 2 $1-1=$ CYFRA 2 $1-1$ after two cycles of chemotherapy; $\mathrm{Cl}=$ confidence interval; $\mathrm{ECOG} P S=$ Eastern Cooperative Oncology Group performance status; $M S=$ median survival time; NSCLC = non-small-cell lung cancer; NP = non-progression; $O R=$ objective response 
response. In this subgroup, the CYFRA 21-1 declines, best correlating with NP and OR corresponded to $a \geqslant 35$ and $\geqslant 62 \%$ reduction in CYFRA 21-1 after two chemotherapy courses (marker response-35 and marker response-62, respectively).

The cut-off $\geqslant 35 \%$ was $84.6 \%$ sensitive and $79 \%$ specific in the diagnosis of NP (accuracy, 82.2\%). Marker response-35 was achieved in 22 out of $26 \mathrm{NP}$ patients but only in 4 out of $19 \mathrm{PD}$ patients $(P<0.0001)$. Response-35 conferred a longer survival (14.0 months $v s 6.1$ months, $P=0.0002$ ).

Marker response- 62 was $90 \%$ sensitive and $60 \%$ specific with regard to OR (accuracy, 66.7\%). It occurred in 9 out of $10 \mathrm{OR}$ and in 14 out of $35 \mathrm{NR}$ patients $(P=0.02)$. Patients who had $\geqslant 62 \%$ CYFRA 21-1 reduction survived 14 vs 6.6 months for those who had a lesser decrease $(P=0.02)$.

Non-progression patients showed a far better survival as compared to PD patients (14.0 vs 6.1 months, $P<0.0001)$. Survival difference between OR and NR patients was not significant $(P=0.3)$.

When PS, marker response- 35 and NP were included in the Cox model, only marker response-35 (RR: $0.4 ; 95 \%$ CI $0.2-0.8$; $P=0.01$ ) and NP (RR: $0.6 ; 95 \%$ CI $0.4-0.9 ; P=0.01$ ), but not PS (RR: $1.8 ; 95 \%$ CI $0.9-3.5 ; \quad P=0.11$ ), remained significant determinants of survival.

We investigated the prognostic role of CEA changes during chemotherapy as well. In the univariate analysis, CEA response $(\geqslant 35 \%$ decline) was found to be associated with prolonged survival (14.0 vs 8.8 months; $P=0.04$ ). Being included in the Cox model with PS and NP, CEA response, however, did not retain significance $(P=0.78)$.

\section{DISCUSSION}

This is the first study comparing the prognostic impact of two clinical response category groups, namely OR and NP, with two corresponding CYFRA 21-1 responses differing in magnitude of decline.

Our study together with a previous report (Lara et al, 2006) questions the validity of $\mathrm{OR}$ as a survival indicator. It shows the survival of SD standing more close to $\mathrm{OR}$ than to PD patient

\section{REFERENCES}

Ardizzoni A, Cafferata MA, Tiseo M, Filiberti R, Marroni P, Grossi F, Paganuzzi M (2006) Decline in serum carcinoembryonic antigen and cytokeratin 19 fragment during chemotherapy predicts objective response and survival in patients with advanced nonsmall cell lung cancer. Cancer 107: 2842-2849

Armitage P (1971) Statistical Methods in Medical Research. Oxford, England: Blackwell

Cox DR (1972) Regression models and life-tables. J R Stat Soc 34: 187-202

Ebert W, Muley T (1999) CYFRA 21-1 in the follow-up of inoperable nonsmall cell lung cancer patients treated with chemotherapy. Anticancer Res 19: $2669-2672$

Gandara DR, Edelman MJ, Lara P, Lau D (1999) Current status and novel therapeutic approaches in advanced non-small cell lung cancer. ASCO Educational Book Spring, pp 362-369

Lara PN, Redman MW, Kelly K, Edelman MJ, Williamson SK, Crowley JJ, Gandara DR (2006) Alternative measures predicting clinical benefit in advanced non-small cell lung cancer (NSCLC) from Southwest categories, suggesting that a stable disease by NSCLC chemotherapy contributes significantly to patients' survival. Thus, NP $(\mathrm{PR}+\mathrm{SD})$ appears to measure treatment efficacy more accurately than traditional OR.

In the study, we found that chemotherapy-induced CYFRA 21-1 changes had a strong association with both radiological response (OR, SD and PD) and survival. Furthermore, the CYFRA 21-1 change at SD were closer to that in $\mathrm{OR}$ than in $\mathrm{PD}$, corroborating Ebert and Muley (1999) study of inoperable NSCLC patients.

In addition to known unfavourable prognostic implication of high pretreatment CYFRA 21-1 in advanced NSCLC (Pujol et al, 2004), we have observed that therapy-induced 2-CYFRA 21-1 impacts survival even more. Inclusion of 2-CYFRA 21-1 and NP in the Cox model replaced pretreatment CYFRA 21-1, PS and stage of disease, becoming the major determinants of survival with relative risks 0.40 and 0.55 , respectively.

In the subgroup of 45 patients with serologically assessable disease, the marker declines best associated with clinical OR and NP outcomes comprised 62 and 35\%, respectively.

Clinically, NP is more meaningful than OR; interestingly, marker response-35 reflected NP and survival better than marker response-62 for OR and survival. We suggest that NP, incorporating $\mathrm{SD}$, really groups the patients benefiting from therapy. These two parameters have an independent impact as prognostic factors for survival.

High accuracy of the marker response-35 in diagnosis of NP and its strong association with survival makes it possible to use it as a reliable surrogate marker of treatment efficacy in advanced NSCLC, and a tool to be considered in the design of future NSCLC trials.

We are aware of the small cohort of patients in this study, which limits the power of multivariate analyses and thus warrant validation and refinement by larger scale prospective trials.

\section{ACKNOWLEDGEMENTS}

We thank Dr Mario Baras of the Hebrew University, Hadassah School of Public Health, for advice on the statistical analysis.

Oncology Group (SWOG) randomized trials: implications for clinical trial design. J Clin Oncol ASCO, Annual Meeting Proceedings; 24(18s): 7006

Martini N, Kris MG, Gralla RJ, Bains MS, McCormack PM, Kaiser LR, Burt ME, Zaman MB (1988) The effects of preoperative chemotherapy on the resectability of non-small cell lung cancer with mediastinal lymph node metastases (N2 M0). Ann Thorac Surg 45: 370-379

Nisman B, Lafair J, Heching N, Lyass O, Baras M, Peretz T, Barak V (1998) Evaluation of tissue polypeptide specific antigen, CYFRA 21-1, and carcinoembryonic antigen in nonsmall cell lung carcinoma: does the combined use of cytokeratin markers give any additional information? Cancer 82: $1850-1859$

Pujol JL, Molinier O, Ebert W, Daures JP, Barlesi F, Buccheri G, Paesmans M, Quoix E, Moro-Sibilot D, Szturmowicz M, Brechot JM, Muley T, Grenier J (2004) CYFRA 21-1 is a prognostic determinant in non-small-cell lung cancer: results of a meta-analysis in 2063 patients. Br J Cancer 90: 2097-2105 